\title{
EFFECT OF CRYOFORGING ON MECHANICAL PROPERTIES OF LOW SFE CAST BRASS
}

\author{
DASHARATH. S. M $^{1}$, SUHRIT MULA ${ }^{2}$ \& SACHINKUMAR PATIL ${ }^{3}$ \\ ${ }^{1,3}$ School of Mechanical Engineering, Reva University Bangalore, India
}

${ }^{2}$ Department of Metallurgical and Materials Engineering, Indian Institute of Technology, Roorkee, Uttarakhand, India.

\begin{abstract}
Cast brass with a composition of $\mathrm{Cu}-9.6 \% \mathrm{Zn}$ was forged at nitrogen temperature after homogenization annealing up to the most extreme conceivable decrease in the zone. At greatest disfigurement condition, a significant $\sim 12$ times change of yield strength and hardness was achieved for both the combinations contrasted with that of the homogenized alloy. Alloying of $\mathrm{Zn}$ in $\mathrm{Cu}$ decreases the $\mathrm{SFE}$ of $\mathrm{Cu}$ and it can be exceptionally compelling to anticipate dynamic recuperation and limits cross slip to happen. In this way, it enhances twining action for advance misshapening. TEM examination revealed that the developments of subgrains and additionally nanotwins are in charge of the enhanced strength and ductility.

KEYWORDS: Cast Brass, Cryoforging, Ultrafine Grain, Nanotwins, Dislocation Substructure \& Electron Microscopy
\end{abstract}

Received: Jul 24, 2018; Accepted: Aug 14, 2018; Published: Nov 19, 2018; Paper Id.: IJMPERDSPL201837

\section{INTRODUCTION}

Copper and its alloys have the higher thermal and electrical conductivity, machinability, high formability and consumption obstruction properties, and so on, because of this; these combinations have been exhaustively utilized as a part of heat exchanger tubes, heating, and cooling frameworks, consumable water funnels and different regions [1, 2]. Ultra-fine grained (UFG) brasses have one of a kind mechanical properties and physical properties when contrasted with its coarse-grained counterpart. These ultra-fine grained materials have the huge grain limit, these limits, going about as obstructions to the disengagement movement and draw out the extensive augmentation in the strength. Sever plastic deformation techniques, for example, high pressure torsion [30], Accumulative roll bonding [31], Equi-channel angular pressing (ECAP)[32], Multi-axial forging (MAF) [6], Cryorolling (CR) [26] ball milling and so forth have been produced and viably connected to empower the ultra-fine grained structures in the previous decades. In spite of the fact that these techniques have been broadly used to create thermally stable ultrafine/nanostructured grain morphology with enhanced mechanical properties [4], the weaknesses are because of the necessity of costly and low efficiency related with these strategies [5]. Out of over these, MAF is a straightforward handling strategy in which the material experiences continued manufacturing in three symmetrical ways. The benefit of MAF is that the first shape the stays same with slightest bending even after a few cycles. Contrasted and the MAF at room temperatures or at elevated temperatures, concealment of dynamic recuperation and recrystallization amid disfigurement at cryogenic temperatures safeguards a high thickness of imperfections created by distortion, which can go about as the potential recrystallization locales. As needs are, the cryogenic disfigurement requires less plastic distortion for accomplishing ultra-fine grained structure, contrasted with the SPD forms at room temperature [3]. 
It can be noticed that a more work was accomplished on the development of UFG in the high stacking fault energy materials. There is a lacking of identified with an arrangement of UFG structure and break component of the low stacking energy issue vitality copper-based alloy produced by multi-axial forging. In this manner, the primary goal of the present work is to explore the mechanical properties and fracture of the UFG $\mathrm{Cu}-9.8 \mathrm{wt} . \% \mathrm{Zn}$ alloy produced by cryoforging. The impact of aggregate strain on hardness and mechanical properties of the alloy was inspected through the Vickers hardness testing and tensile testing. A methodical report on microstructural development with expanding endures mesoscale and microscale by utilizing the optical microscopy and transmission electron microscopy was made in the present work.

\section{Experimental Details}

The composition of $9.8 \mathrm{wt} . \% \mathrm{Zn}$ samples were forged at $77 \mathrm{~K}$ utilizing friction screw forgingmachine at a strain rate of $10 \mathrm{~s}-1$. The multi-axial forging at cryogenic temperature was performed by filling the chamber with fluid nitrogen and its level was kept up to test stature amid producing. Figure 1 demonstrates the schematic outline of MAF for a solitary cycle. Strain per pass is settled as $\Delta \varepsilon i=0.2$ (where ' $n$ ' number of passes) and kept up steady all through all passes. The total strain after one cycle of MAF was $\Sigma \Delta \varepsilon n=1=0.6$ (where ' $n$ ' is a number of cycles). In the present investigation, MAF was done to aggregate strains of 3.0, 5.4, 7.2 i. e., 5, 9, 12 cycles, respectively. Tests were effectively forged up to 12 cycles with no splitting, After MAF, tests were set up by separating along the plane opposite to the last producing pivot i. e., the most noteworthy measurement side. Microstructure advancement and mechanical properties were considered after MAF at various combined strains $(\Sigma \Delta \varepsilon n=5=3.0, \Sigma \Delta \varepsilon n=9=5.4, \Sigma \Delta \varepsilon n=12=7.2)$. Tensile samples were set up according to ASTM: E8 sub estimate with $10 \mathrm{~mm}$ gauge length. The samples were machined at the focal point of the produced tests. Uniaxial tensile tests were led with a steady strain rate of $2 \times 10-4 \mathrm{~s}-1$ utilizing a Tinius Olsen machine of $25 \mathrm{kN}$ limit. A microstructural investigation was done by optical microscopy and TEM examination. The optical microstructure was analyzed utilizing a LEICA DMI $5000 \mathrm{M}$ optical magnifying instrument. Some selected samples were cut for TEM consider from the focal point of the produced example. Electrojet polishing was performed in an FEI twin fly electro polisher (worked at $40 \mathrm{~V}$ ) utilizing an etchant of methanol $+20 \%$ nitric acid kept up at - $40^{\circ} \mathrm{C}$ temperature. TEM examination was completed utilizing FEI Technai 20 G2S-Twin transmission electron microscopy instrument worked at $200 \mathrm{kV}$. Fractography and break component investigation after the ductile test was done utilizing a scanning electron microscopy (ZEISS, 51-ADD0048).

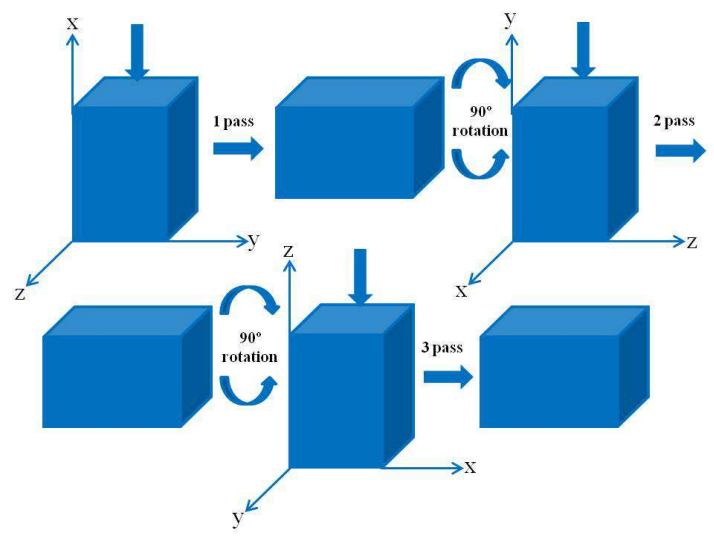

Figure 1: Multiaxial Forging Diagram with Corresponding One Cycle 


\section{RESULTS AND DISCUSSIONS}

\section{Microstructural Characterization}
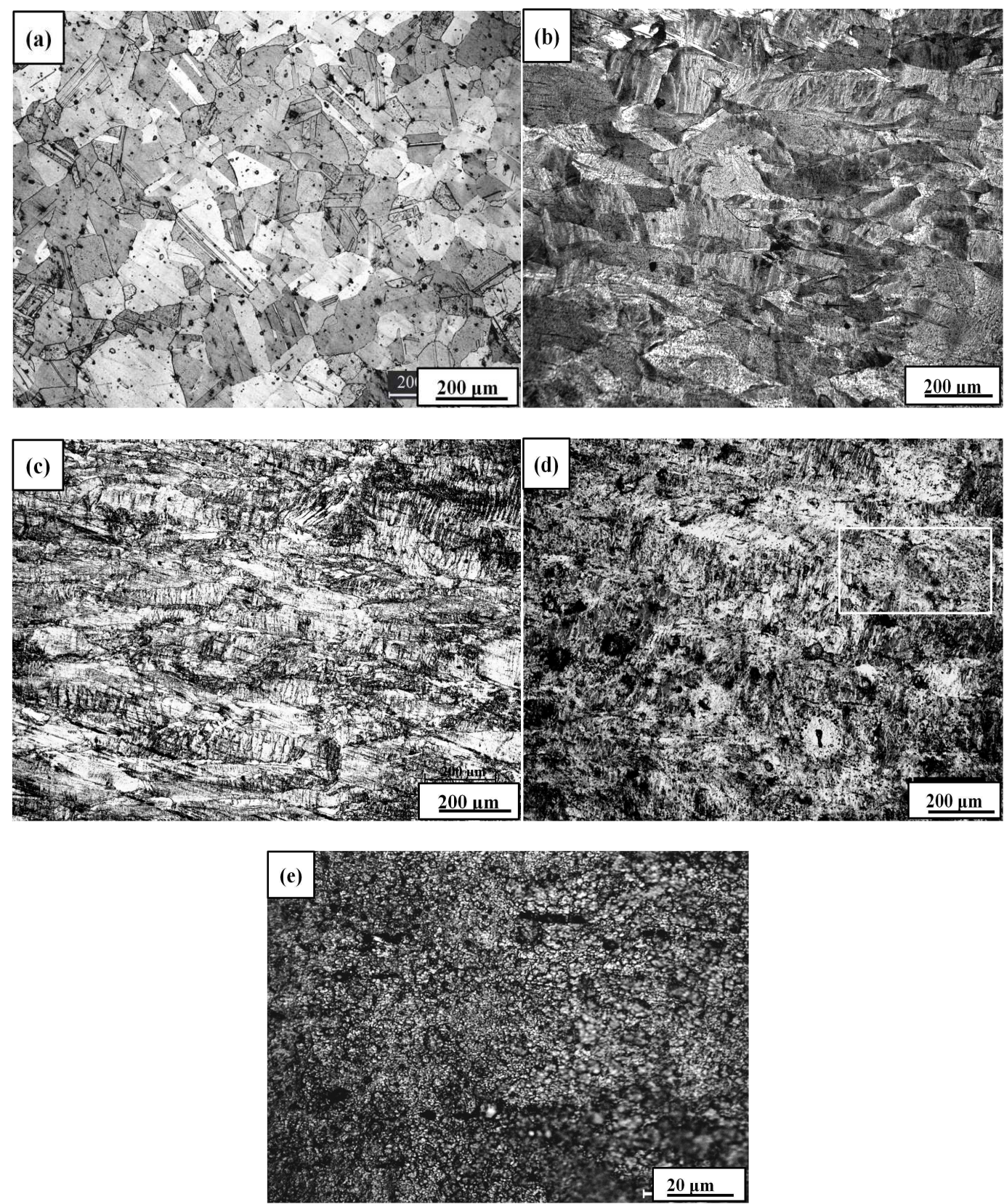

Figure 2: Microstructures of: (a) As-Cast Homogenized Annealed (b) 5 Cycles; (c) 9 Cycles; (d and e) 12 Cycles

Figure 2. demonstrates the optical micrograph of the as homogenized and cryoforged samples. An equiaxed grain with few twins can be seen from the homogenized annealed samples as appeared in Figure 2a. A normal grain size of the as homogenized samples was estimated from the optical magnifying lens utilizing line catch strategy. The normal grain estimate was estimated to be $90 \pm 10 \mu \mathrm{m}$. It can be seen from the cryoforged sample (Figure $2 \mathrm{~b}$, c, and d) that number of cycles increments with expanding the shear/disfigurement groups and there is a grain limit was equivocal and condition between the grain insides. The combination MAF at the total strain of 3.0 (5 cycles) demonstrated the twisted microstructure comprising of shear/misshapening groups in the distinctive ways. With expanding the MAF cycles up to 9, the disfigurement groups thickness has expanded further and S-band development was observed. Comparative highlights 
were seen in the MDF of unadulterated copper at $195 \mathrm{~K}$ by kobayashi et al [12]. Despite the fact that, these reviews are in concurrence with the Rao et al [7] wrote about MDF of the AA6061 compound at LN2 temperature. MAF at LN2 up to 12 cycles, the microstructure got full distorted and loaded with twisting groups and equiaxed fine grains. Seen from Figure $2 \mathrm{~d}$ and e, the band size was decreased and little-equiaxed grains was framed this may because of the high thickness of distortion groups with expanding the MAF strain. Under serious plastic twisting at low temperatures, a few geometrically fundamental limits (GNBs, for example, smaller scale groups or disfigurement groups [13] are effectively created. The common intersection, number of disfigurement groups and misorientation of misshapening groups increments with strain; at long last bringing about development of new fine grains [14-15]. Fundamentally, the optical micrographs demonstrate profoundly distorted structures, and it isn't conceivable to uncover the point by point microstructural highlights from the optical micrograph.
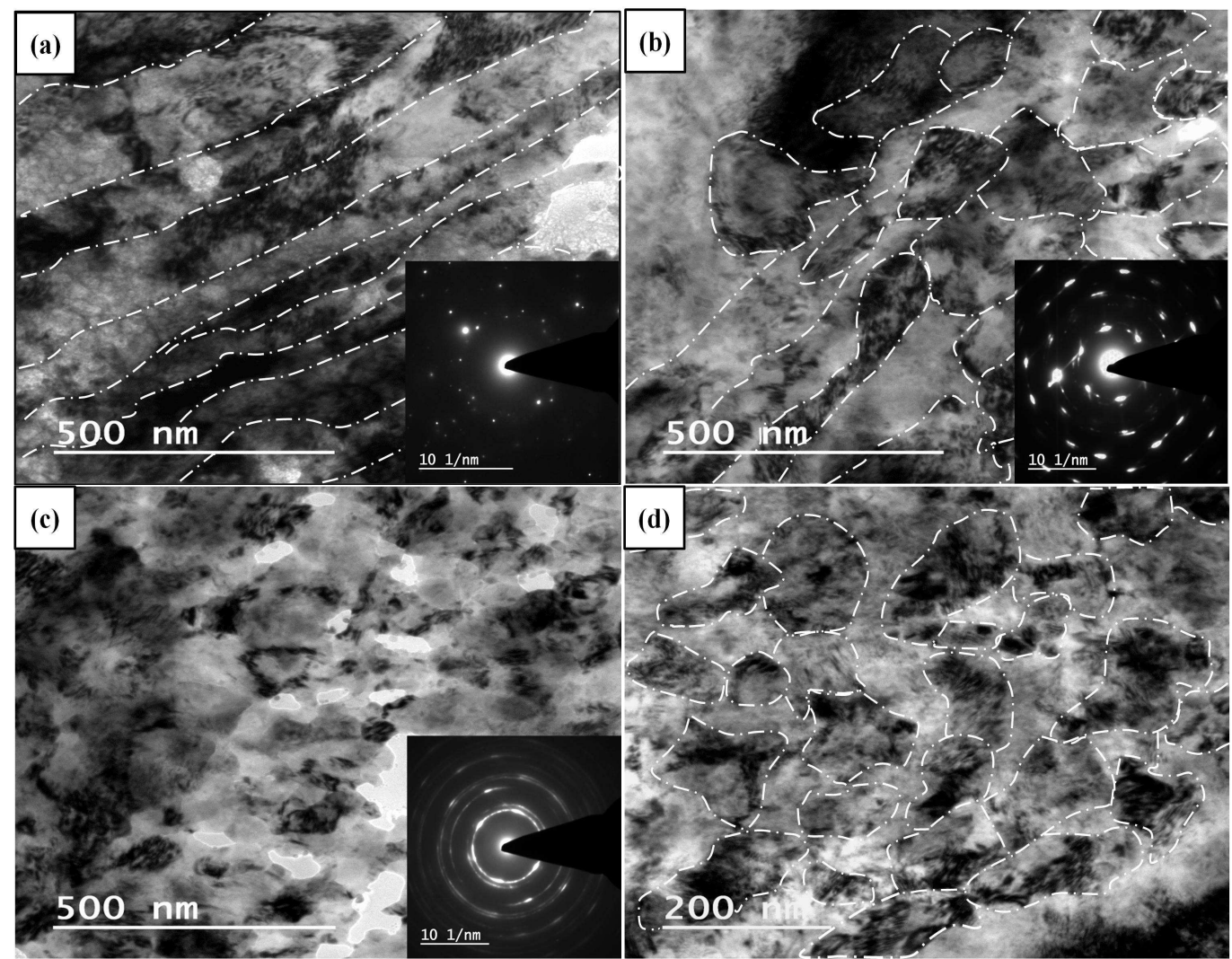

Figure 3: Transmission Electron Micrographs of (a) 5 Cycles; (b) 9 Cycles; (c) and (d) 12 Cycles

Figure 3. demonstrates the TEM micrograph and relating SAD example of the cryoforged with a various number of cycles and cryoforged+annealed samples. It can be seen from Figure 3 that with expanding the number of cycles with a relating diminishes in the subgrain size. An arrangement of subgrain with a normal size of 700nm alongside nearness of high thickness separations was seen from the Figure 3a. Likewise, the example cryoforged up to 5 cycles showed a fine and elongated grain structure. The SAD micrograph appeared (as inset) in a Figure 3a uncovers the nearness of low angle grain limits. Figure $4 \mathrm{~b}$ demonstrates the microstructure comparing to MAF up to 9 cycles, where the subgrain with the normal size of $320 \mathrm{~nm}$ was observed. The separation thickness has expanded with expanding the strain and concealment of dynamic recuperation prompts development of fine subgrain structure from the elongated fine subgrain structure. Additionally, halfway stretched subgrains and incompletely equiaxed grains were seen from the microstructure (Figure $3 \mathrm{~b}$ ). The SAD micrograph appeared (as inset) in a Figure $3 \mathrm{~b}$ irregular rings with for the most part expanded 
brighter regions. The expanded brighter areas are because of the diffraction from the coarser recrystallized grains, while the thin parts of the rings are because of the nearness of littler size grains [27]. The microstructure comparing to 12 cycles MAF have appeared in the Figure $3 \mathrm{c}$ and d. In Figure 3(d), the microstructure demonstrates almost equiaxed fine grain structure with a normal size of $170 \mathrm{~nm}$. Sub-grains are shaped about equiaxed structure with thick disengagement dividers. The comparing SAD example of Figure 3d (in inset) demonstrates that microstructure contains the high point grain limits. Besides, the SAD sample of the micrograph (Figure 3d) shows more nonstop yet expanded rings contrasted with that of the 5 and 9 cycles (Figure $3 \mathrm{a}$ and b) proposing expanding misorientation angle (high point grain limit) and diminishing grain/subgrains size in the 12 cycles. With expanding the strain from the 3.0 to 7.2 the lamellar grain structure with low angle grain limits gradually changing to equiaxed grain structure with high angle grain limits are apparent from the Figure 3c. With expanding the strain, the misorientation between the separation limits has expanded changed into high angle grains. These high point grain limits give a grain limit reinforcing (Hall - Petch equation) to the material. Indeed, even at high aggregate strains $(\Sigma \delta \varepsilon n=12=7.2)$, the nearness of separation inside the subgrains alongside high thickness of disengagement zones are observed. This may because of preparing at LN2 temperature prompts concealment of dynamic recuperation and recrystallization. After 12 cycles, MAF arrangement of equiaxed grain structure with high angle and the nearness of high separation densities prompt grain limit reinforcing and disengagement fortifying to the material.

\section{Mechanical Properties}

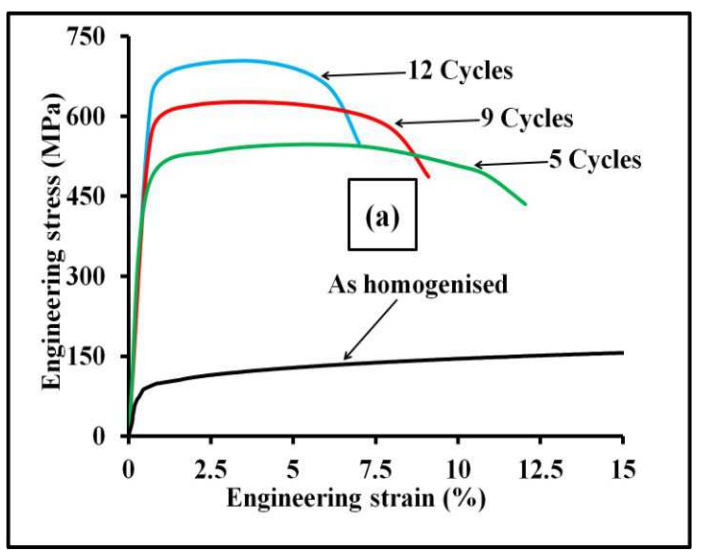

Figure 5: Engineering Stress-Strain Curves of as Received and MAF Specimens

Figure 5 demonstrates the mechanical behavior of the as homogenized, cryoforged and cryoforged+annealed $\mathrm{Cu}-9.8 \% \mathrm{Zn}$ combination. It can be seen from the pliable bend (Figure 5a) the yield strength is incremented with expanding the number of cycles and comparing diminish in the ductility. The homogenized sample has demonstrated the most minimal yield strength (YS=70 MPa) and extreme strength (UTS= $170 \mathrm{MPa}$ ) with $38 \%$ extension. In the wake of cryoforging up to 5 cycles, YS and UTS were observed to be 495 and $544 \mathrm{MPa}$, respectively. Advance distortion of the sample to 9 cycles, the YS and UTS additionally expanded to 593 and $622 \mathrm{MPa}$, respectively. YS and UTS of a similar material with greatest cycles of 12 under LN2 were estimated to be 680 and $702 \mathrm{MPa}$, respectively. The mechanical strength (YS and UTS) of the homogenized samples took after by throwing expanded because of the strong arrangement reinforcing. Alloying components in the strong arrangement cause versatile contortion in the parent cross-section. The cross-section mutilations go about as obstructions to disengagement movement [17]. The expansion in quality with expanding strain is in correspondence with the increment in the hardness. This upgrade in the YS is because of the fortifying by the arrangement of subgrain limit, disengagement alloying and strong arrangement reinforcing. Forging at 
liquid nitrogen temperature brings about concealment of dynamic recuperation, higher disengagement thickness, advancement of twin movement, and consequently, it is normally a higher quality joined by great ductility. The stacking fault energy of the present combination is $\sim 17 \mathrm{~mJ} / \mathrm{m} 2$ [18]. Lessened stacking shortcoming vitality upsets disengagement development by slip, and consequently, twinning activity is favored for plastic disfigurement. Along these lines, it is accounted for to enhance work solidifying rates and cause the synchronous increment in strength and ductility [19]. Since the realistic least grain size is corresponding to stacking issue vitality, low stacking issue vitality gives better grain refinement and upgraded mechanical properties contrasted with high SFE amalgams [20, 21]. Then again, the material after 12 MAF cycles, advancement of fine subgrain structure and change of low angle grain limits to high angle grain size are observed.

\section{Fracture Morphology}

Figure 6 demonstrates the crack surface morphology of the $\mathrm{Cu}-9.8 \% \mathrm{Zn}$ combination homogenized and subjected to a various number of MAF cycles. It can be seen from Figure 8, the dimple estimate step by step diminish with expanding the number of cycles. The beginning (homogenized) samples cracked in a bendable way uncovering very much created dimples over the whole surface. The bigger size dimples can be found in the fractographs in Figures 8(a). After 5 cycles, the dimples measure diminished to $9 \mu \mathrm{m}$. The examples cryoforged to 9 and 12 cycles, the dimple estimate diminished to 3 and $2 \mu \mathrm{m}$, individually. The diminish in dimple measure in the most extreme cryoforged samples is because of the work solidifying and conceivable grain estimate refinement, comparative sort of results detailed for the seriously cryo disfigured materials $[22,23]$.

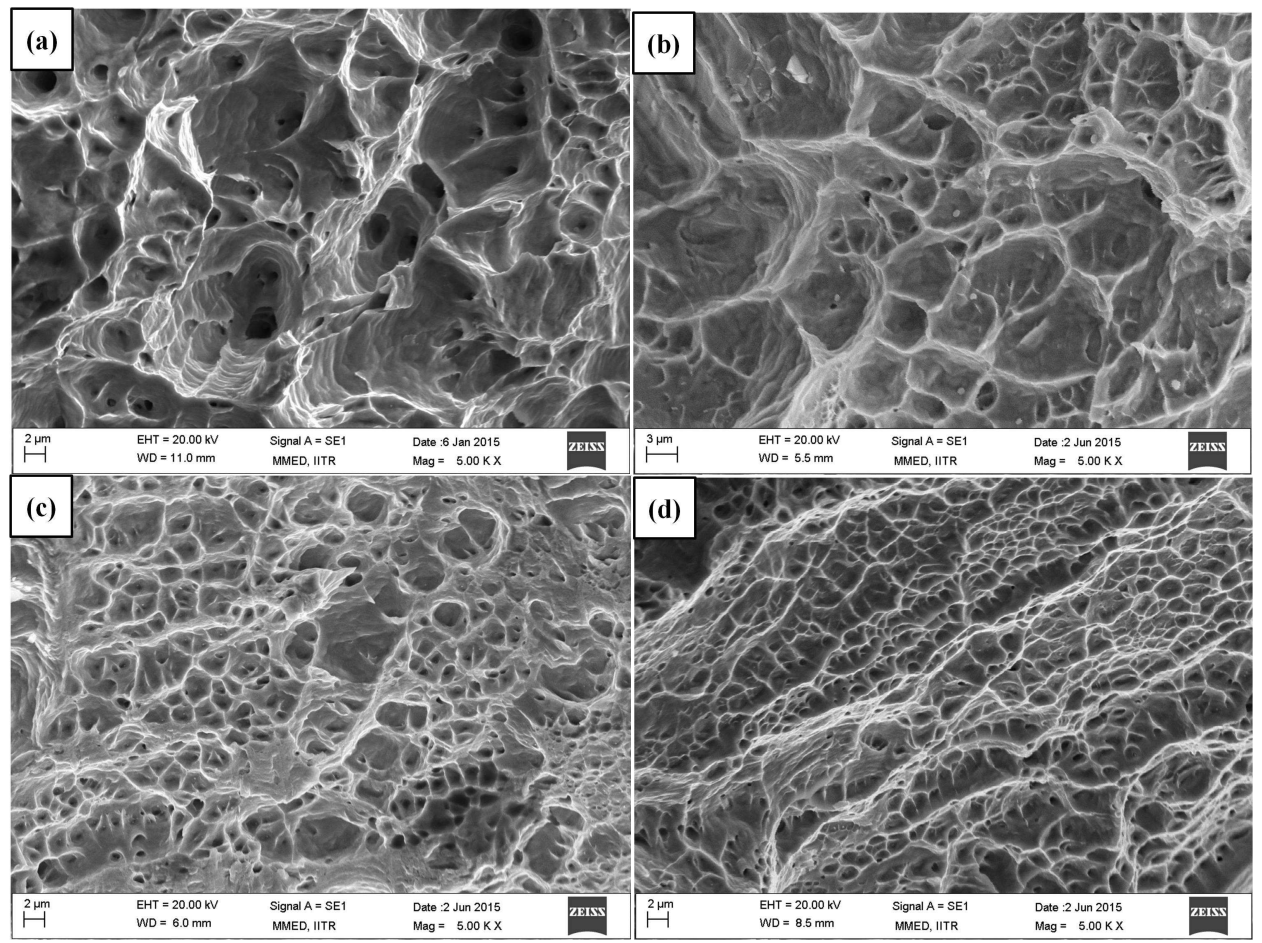

Figure 6: Fractography of Cu-9.8\% Zn Alloy. (a) As Homogenized (b) 5 Cycle (c) 9 Cycle (d) 12 Cycle

\section{CONCLUSIONS}

Multiaxial forging (MAF) on Cu-9.8\% $\mathrm{Zn}$ amalgam at LN2 has been effectively done up to aggregate strains of 3.0, 5.4 and 7.2. Microstructure and Mechanical properties are investigated and the accompanying conclusions are drawn: 
- Distortion is produced in different ways on each after cycles of MAF $(\Sigma \delta \varepsilon n=5=3.0)$ and the thickness of these distortion groups has expanded with expanding combined strain up to 5.4 and 7.2.

- Cryoforged sample of $9.8 \% \mathrm{Zn}$ combination with 12 cycles demonstrated the most noteworthy estimation of mechanical properties (YS-680 MPa, ductility 7\%) when contrasted with that of the homogenized alloy. This is because of the immersion of separations thickness and refinement of grain estimate in view of low SFE.

- Fractography investigation of cryoforged (12 cycles) tests demonstrated a weak appearance break with few dimple marks while in the wake of strengthening of same demonstrated more dimple burst on the crack surface showing increment in pliability. This is likewise validated the ductile conduct of the cryorolled and annealed samples.

\section{REFERENCES}

1. Xavier, J. R.. Nallaiyan, R. Corrosion inhibitive properties and electrochemical adsorption behaviour of some piperidine derivatives on brass in natural sea water. Journal of Solid State Electrochemistry. Volume 16, Issue 1, January 2012, Pages 391-402.

2. Shi, P. Wang, Q. Xu, Y. Luo, W. Corrosion behavior of bulk nanocrystalline copper in ammonia solution. Materials Letters. Volume 65, Issue 5, 15 March 2011, Pages 857-859.

3. Y. Wang, M. Chen, F. Zhou and E Ma: High tensile ductility in a nanostructured metal, Nature, 2002, vol. 419, pp.912-915. $\mathrm{ZO}$

4. M. Eizadjou, H. D. Manesh, K. Janghorban: Microstructure and mechanical properties of UFG Al strips produced by ARB process, Journal of Alloys and Compounds, 2009, vol. 474, pp. 406-415.

5. Han B J. Ultrafine grained Fe32\% Ni alloy processed by multiaxial forging [J]. Advanced Materials Research, 2010, 97: 187190.

6. Padap a K, Chaudhari G P, Pancholi V, Nath S K. Warm multiaxial forging of AISI 1016 steel [J]. Materials and Design, 2010, 31: 38163824.

7. Rao P N, Singh D, Jayaganthan R. Mechanical properties and microstructural evolution of Al 6061 alloy processed by multidirectional forging at liquid nitrogen temperature [J]. Materials and Design, 2014, 56: 97104.

8. Cherukuri B, Srinivasan R. Properties of AA 6061 processed by multi axial compression/forging (MAC/F) [J]. Materials and Manufacturing Processes, 2006, 21: 519525.

9. Tang L, Liu C, Chen Z, JI D, Xiao H. Microstructures and tensile properties of MgGdYZr alloy during multidirectional forging at $773 \mathrm{~K}$ [J]. Materials and Design, 2013, 50: 587596.

10. Zherebtsov S, Kudryavtsev E, Kostjuchenko S, Malysheva S, Salishchev G. Strength and ductility-related properties of ultrafine grained two-phase titanium alloy produced by warm multiaxial forging [J]. Materials Science and Engineering A, 2012, 536: 190196.

11. Belyakov A, Sakai T, Miura H, Tsuzaki K. Grain refinement in copper under large strain deformation [J]. Philosophical Magazine A, 2001, 81: 26292643.

12. Abu-Hashim, M. S. D., Salama, A., \& Garbout, A. (2015). Characterization Of Soil-Root Interactions Using Medical X-Ray Computed Tomography Technique. International Journal Of Agricultural Science And Research (Ijasr), 5(5), 159-170. 
13. Kobayashi C, Sakai T, Belyakov A, Miura H. Ultrafine grain development in copper during multidirectional forging at 195 K. Philos Mag Lett 2007;87:751-66.

14. B. Bay, N. Hansen, D. A. Hughes, D. Kuhlmann-Wilsdorf: Evolution of FCC deformation structures in polyslip, Acta Metall. Mater., 1992, vol. 40, pp. 205-219.

15. A. Belyakov, H. Miura and T. Sakai: Fine-Grained Structure Formation in Austenitic Stainless Steel under Multiple Deformations at 0.5 Tm, Mater. Trans., JIM, vol. 41, 2000, pp. 476-484.

A. Belyakov, T. Sakai, H. Miura and K. Tsuzaki: Effect of initial microstructures on grain refinement in a stainless steel by large strain deformation Philosophical Magazine A81, 2001, vol. 11, pp. 2629-2643.

16. Ungar, Microstructural parameters from X-ray diffraction peak broadening, Scr. Mater. 51 (2004) 777-781.

17. Naga Krishna N, Tejas R, Sivaprasad K, Venkateswarlu K. Study on cryorolled Al-Cu alloy using X-ray diffraction line profile analysis and evaluation of strengthening mechanisms. Mater. Des. 2013;52:785-790.

18. M. F. Denanot, J. P. Villain, The stacking fault energy in Cu-Al-Zn alloys, Phys. Status Solidi A, 8 (1971) $125-127$.

19. Y. H. Zhao, Y. T. Zhu, X. Z. Liao, Z. Horita, T. G. Langdon, Tailoring stacking fault energy for high ductility and high strength in ultrafine grained Cu and its alloy, Appl. Phys. Lett. 89 (2006) 121906.

20. W. S. Zhao, N. R. Tao, J. Y. Guo, Q. H Lu, K. Lu, Simultaneously High density nano-scale twins in Cu induced by dynamic plastic deformation, Scripta Mater. 53 (2005) 745-749.

21. F. A. Mohamed, A dislocation model for the minimum grain size obtainable by milling, Acta Mater. 51 (2003) 4107-4119

22. Wang ZC, Prangnell PB. Microstructure refinement and mechanical properties of severely deformed Al-Mg-Li alloys. Mater Sci Eng A 2002;328:87-97.

23. Panigrahi SK, Jayaganthan R. A study on the mechanical properties of cryorolled Al-Mg-Si alloy. Mater. Sci. Eng. A2008;480:299-305. 